ИЗВЕСТИЯ АКАДЕМИИ НАУК ЭСТОНСКОИ ССР. ФИЗИКА * МАТЕМАТИКА

PROCEEDINGS OF THE ACADEMY OF SCIENCES OF THE ESTONIAN SSR. PHYSICS * MATHEMATICS

$1987,36,1$

Х. КОППЕЛ, И. РАММО, П. ЛЫУК, В. ВАБСОН, Н. ЛЫЧАГИНА, Е. КАРАТАЕВ, И. ФЕЩЕНКО, Ю. ГАТ ИЛОВ, В. ПЕРОВ

\title{
ВЫРАЩИВАНИЕ ЭПИТАКСИАЛЬНЫХ ПЛЕНОК АРСЕНИДА ГАЛЛИЯ СОВМЕСТНЫМ ТЕРМИЧЕСКИМ РАЗЛОЖЕНИЕМ ПАРОВ ТРИМЕТИЛГАЛЛИЯ И ТРИЭТИЛАРСИНА
}

H. KOPPEL, I. RAMMO, P. LOUK, V. VABSON, I. LOTSAGINA, E. KARATAJEV, I. FESTSENKO, J. GATILOV, V. PEROV. GALLIUMARSENIIDI EPITAKSIAALKILEDE KASVATAMINE TRIMETUOLGALLIUMI JA TRIETUOLARSIINI AURUDE OHISEL TERMILISEL LAGUNDAMISEL

H. KOPPEL, I. RAMMO, P. LOUK, V. VABSON, I. LYCHAGINA, E. KARATAYEV, I. FESHCHENKO, J. GATILOV, $V$. PEROV. GROWTH OF GALLIUMARSENIDE EPITAXIAL LAYERS BY COMBINED THERMAL DECOMPOSITION OF TRIMETHYLGALLIUM AND TRIETHYLARSINE VAPOURS

\section{(Представил К. К. Ребане)}

При выращивании эпитаксиальных структур на основе соединений типа $\mathrm{A}^{3} \mathrm{~B}^{5}$ широко применяется метод газовой эпитаксии, основанный на термическом разложении металлоорганических соединений. Обычный MOC-гидридный метод, где источником элементов пятой группы являются гидриды, позволяет получить эпитаксиальные слои, не уступающие по качеству слоям, полученным методом жидкофазной эпитаксии. Получены также сверхтонкие слои, сравнимые по толщине со слоями, полученными методом молекулярных пучков [ $\left.{ }^{1}\right]$, причем аппаратура газовой эпитаксии менее сложна, чем в случае метода молекулярных пучков.

Однако наряду с явными положительными моментами МОС-гидридный метод обладает серьезным недостатком, закльчающимся в высокой токсичности применяемых гидридов - арсина и фосфина.

В поиске более безопасных исходных веществ ученые обратились к алкильным соединениям соответствующих элементов $\left[{ }^{2}\right]$. Алкильные соединения элементов третьей и пятой групп образуют между собой соединения с донорноакцепторной связью

$$
A R_{3}+B R_{3}^{\prime} \rightarrow R_{3} A \cdot B R_{3}^{\prime} \text {. }
$$

Многие из таких соединений разлагаются при температурах, подходящих для выращивания эпитаксиальных слоев, с образованием соединения типа $\mathrm{A}^{3} \mathrm{~B}^{5}$ и летучих углеводородов. Примером такой реакции может служить

$$
R_{3} A \cdot B R_{3}^{\prime} \stackrel{t^{\circ}}{\rightarrow} \mathrm{AB}+3 R R^{\prime}
$$

Мы исследовали возможность выращивания эпитаксиальных пленок арсенида галлия при нормальном давлении путем совместного термического разложения триметилгаллия и триэтиларсина особой очистки. Триметилгаллий и триэтиларсин очищались методами ректификации п термодистилляции. Массовая доля примесей металлов составляла $10^{-5}$ 
$10^{-6} \%$, а суммарная массовая доля примесей органических веществ $1 \cdot 10^{-1} \%$.

Предполагаемые химические реакции при образовании эпитаксиальных пленок арсенида галлия в случае совместного термического разложения паров триметилгаллия и триэтиларсина следующие:

$$
\begin{aligned}
& \left(\mathrm{CH}_{3}\right)_{3} \mathrm{Ga}+\left(\mathrm{C}_{2} \mathrm{H}_{5}\right)_{3} \mathrm{As} \rightarrow\left(\mathrm{CH}_{3}\right)_{3} \mathrm{Ga} \cdot \mathrm{As}\left(\mathrm{C}_{2} \mathrm{H}_{5}\right)_{3} \text {, } \\
& \left(\mathrm{CH}_{3}\right)_{3} \mathrm{Ga} \cdot \mathrm{As}\left(\mathrm{C}_{2} \mathrm{H}_{5}\right)_{3} \underset{\mathrm{H}_{2}}{\stackrel{\bullet}{\longrightarrow}} \mathrm{GaAs}+3 \mathrm{C}_{2} \mathrm{H}_{6}+3 \mathrm{CH}_{4} \text {. }
\end{aligned}
$$

Не исключены и другие комбинации алкильных радикалов.

Установка для эпитаксии (см. принципиальную схему на рис. 1) изготовлена из нержавеющей стали. Герметизация фланцев достигается фторопластовыми уплотнениями. Горизонтальный кварцевый реактор имеет диаметр 40 и длину 250 мм. Уплотнения реактора сделаны из вакуумной резины. Для подложки из арсенида галлия имеется специальное кварцевое основание, нагреваемое изнутри печью сопротивления.

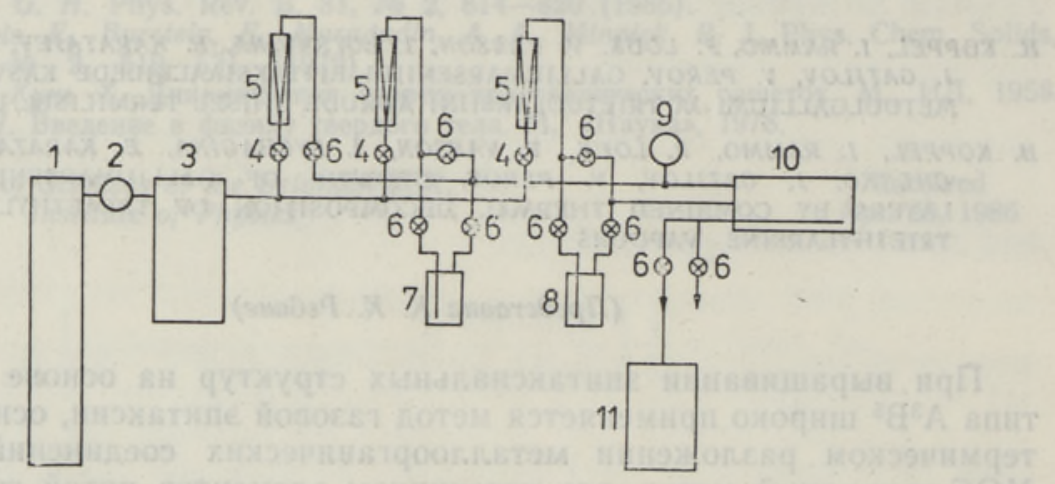

Рис. 1. Принципиальная схема установки эпитаксин. 1 - баллон с водородом, $2-$ редуктор, 3 - очиститель водорода, 4 - регулирующие вентили, 5 - ротаметры, 6 - вентили, 7 - испаритель триметнлгаллия, 8 - испаритель триэтиларсина, 9 мановакуумметр, 10 - реактор, 11 - вакуумный насос.

Выращивание пленок проводили при нормальном давлении. Расход триметилгаллия во время опытов составлял $5 \cdot 10^{-6}-2 \cdot 10^{-5}$ моль/мин, расход триэтиларсина $3 \cdot 10^{-5}-2 \cdot 10^{-4}$ моль/мин, соотношение As : Ga $\geqslant$ $\geqslant 10: 1$. Общий расход водорода составлял $1000-6000$ мл/мин, температура подложек $400-710^{\circ} \mathrm{C}$. В качестве подложек использовали пластинки из полуизолирующего арсенида галлия АГП-4, имеющие ориентацию (100). Были выращены эпитаксиальные слои толщиной от 0,1 до 2 мкм. Толщину пленок определяли микроинтерферометром Линника МИИ-4 по ступеньке на краю пленки. Для получения резкого края пленки в процессе роста на подложку помещали в качестве маски кусок кварцевого стекла. Скорость роста слоев составляла $0,1-1$ мкм/ч. Зеркальная часть пленки имела обычно размеры порядка 10 мм.

Для определения электрических параметров пленок из них вытравливали образцы гантелеобразной формы, а затем проводили измерения проводимости и эффекта Холла методом постоянных тока и магнитного поля. На некоторых из выращенных пленок были измерены также спектры фотолюминесценции. Измерения проводили при 4,2 К. Люминесценцию возбуждали гелий-неоновым лазером ЛГ-75-1 $\quad\left(\lambda_{\text {возб. }}=\right.$ $=632,8$ нм), луч которого модулировался с частотой 273 Гц. Спектральным прибором служил монохроматор THR-1500, а приемником излучения - охлаждаемый до $-60^{\circ} \mathrm{C}$ фотоэлектронный умножитель ФЭУ-83. 
Сигнал фотоумножителя регистрировался селективным усилителем типа 237 фирмы «Unipan» и синхронным детектором типа 232B той же фирмы.

Измерения показали, что электрические свойства пленок сильно зависят от температуры их роста. Оказалось, что пленки, выращенные при температурах ниже $600{ }^{\circ} \mathrm{C}$, имели $p$-тип проводимости с весьма высокой концентрацией $\left(10^{18}-10^{19} \mathrm{~cm}^{-3}\right)$ свободных дырок при их подвижности примерно $125 \mathrm{~cm}^{2} /(\mathrm{B} \cdot \mathrm{c})$. В интервале температур $610-710^{\circ} \mathrm{C}$ получились пленки $n$-типа проводимости. Наивысшее значение подвижности, полученное в этом цикле экспериментов, $-3600 \mathrm{~cm}^{2} /(\mathrm{B} \cdot \mathrm{c})$ при концентрации электронов $5 \cdot 10^{16} \mathrm{~cm}^{-3}$. Согласно $\left[{ }^{3}\right]$, степень компенсации в таких пленках $\sim 0,65$. Этот результат получен при температуре $620^{\circ} \mathrm{C}$; с повышением температуры роста подвижность электронов уменьшается. Около верхней границы (при $710^{\circ} \mathrm{C}$ ) интервала подвижность электронов ниже $100 \mathrm{~cm}^{2} /(\mathrm{B} \cdot \mathrm{c})$ при их концентрации порядка $6 \cdot 10^{17} \mathrm{~cm}^{-3}$. Возможно, что это связано в первую очередь с плохой кристаллической структурой пленки, выращенной в этой области температур. На это указывают спектры фотолюминесценции, измеренные для разных пленок (рис. 2, б и в). Представленный на рис. 2, б спектр относится к пленке,

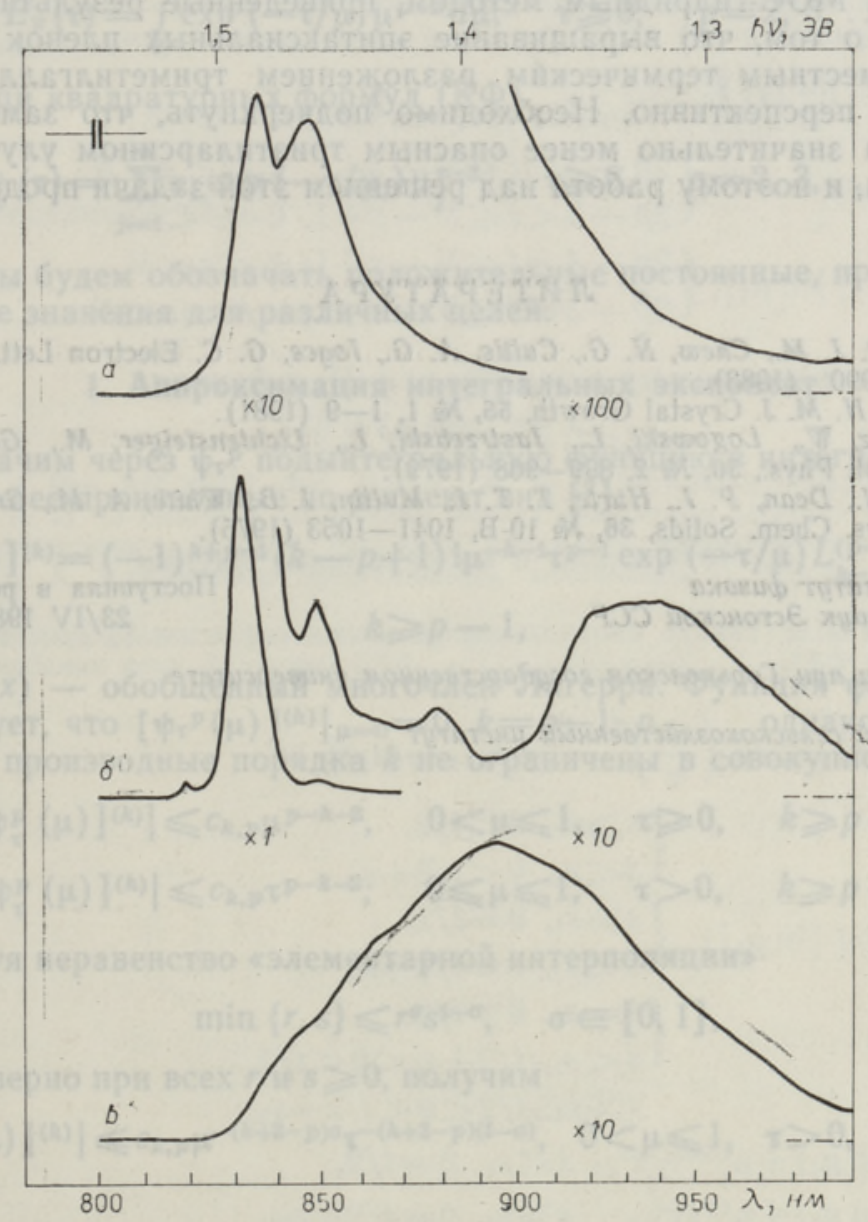

Рис. 2. Спектры фотолюминесценции слоев GaAs, выращенных при -температурах $580^{\circ} \mathrm{C}(a), 620^{\circ} \mathrm{C}$ (б) и $7.710^{\circ} \mathrm{C}($ (в). 
имеющей наивысшую величину подвижности (см. выше). Этот спектр содержит полосы свечения, типичные для монокристаллов или качественных эпитаксиальных пленок. Опираясь на $\left[{ }^{4}\right]$, полосы в спектре свечения можно интерпретировать следующим образом (начиная с более коротких волн): полоса, обусловленная связанным экситоном $(1,514$ эВ), полоса, обусловленная углеродом (а может быть, также бериллием и магнием) (1,4915 эВ), фононное повторение предыдущей полосы $(1,459$ эВ), затем слабая полоса, приписываемая марганцу $(1,409$ эВ), н, наконец, широкая полоса (в области $1,32-1,35$ эВ), обусловленная, вероятно, оловом. Спектр, приведенный на рис. 2, в, принадлежит пленке, выращенной при температуре $710^{\circ} \mathrm{C}$. Здесь можно наблюдать лишь одну широкую полосу, коротковолновый край которой соответствует примерно ширине запрещенной зоны арсенида галлия. Столь широкая и бесструктурная полоса при умеренной концентрации свободных носителей указывает, на наш взгляд, на несовершенную кристаллическую структуру пленки, полученную при этой температуре.

Спектр, приведенный на рис. 2, $a$, принадлежит пленке $p$-типа, выращенной при температуре $580{ }^{\circ} \mathrm{C}$. Концентрация свободных дырок в этой пленке высокая $\left(\sim 10^{19} \mathrm{~cm}^{-3}\right)$, чем объясняется большая ширина видимых на рисунке полос свечения.

Несмотря на то что полученные нами слои еще уступают слоям, полученным MOC-гидридным методом, приведенные результаты свидетельствуют о том, что выращивание эпитаксиальных пленок арсенида галлия совместным термическим разложением триметилгаллия и триэтиларсина перспективно. Необходимо подчеркнуть, что замена опасного арсина значительно менее опасным триэтиларсином улучшает условия труда, и поэтому работа над решением этой задачи продолжается.

\title{
Л ИТЕР А Т Р А
}

1. Griffiths, R. J. M., Chew, N. G., Cullis, A. G., Joyce, G. C. Electron Lett., 19, № 23, 988-990 (1983).

2. Manasevit, H. M. J. Crystal Growth, 55, № 1, 1-9 (1981).

3. Walukiewicz, W., Logowski, L., Jastrzebski, L., Lichtensteiger, M., Gatos, H. C. J. Appl. Phys., 50, № 2, 899-908 (1979).

4. Ashen, D. J., Dean, P. J., Hurle, T. T. J., Mullin, J. B., White, A. M., Greene, P. D. J. Phys. Chem. Solids, 36, № 10-B, 1041-1053 (1975).

\author{
Институт физики \\ Академии наук Эстонской ССР \\ Поступила в редакцию \\ 23/IV 1986
}

НИИ химии при Горьковском государственном университете

Горьковский сельскохозяйственный институт 